\title{
Compact Wideband Antiparallel Diode Frequency Triplers Utilizing Planar Transitions
}

\author{
Wahab Mohyuddin, Kang Wook Kim, and Hyun Chul Choi \\ School of Electronics Engineering, Kyungpook National University, Sankyuk-dong, Buk-gu, \\ Daegu 702-701, Republic of Korea \\ Correspondence should be addressed to Kang Wook Kim; kang_kim@ee.knu.ac.kr
}

Received 9 September 2014; Revised 5 December 2014; Accepted 6 December 2014

Academic Editor: Yuan Yao

Copyright (C) 2015 Wahab Mohyuddin et al. This is an open access article distributed under the Creative Commons Attribution License, which permits unrestricted use, distribution, and reproduction in any medium, provided the original work is properly cited.

\begin{abstract}
Two designs of frequency triplers, which use planar transitions as baluns and an antiparallel diode pair to achieve wide bandwidth, are presented. The ultrawideband transitions are utilized for input and output impedance matching of the frequency triplers. The design process and operation principles are described in this paper. The implemented frequency triplers exhibit flat response over wide frequency range of 3 to $9 \mathrm{GHz}$. The proposed Type A frequency tripler shows conversion loss of $\sim 18 \mathrm{~dB}$ with above $30 \mathrm{~dB}$ even harmonics suppression. With Type B frequency tripler, conversion loss of $\sim 17 \mathrm{~dB}$ and above $25 \mathrm{~dB}$ even harmonic suppression are achieved.
\end{abstract}

\section{Introduction}

Increase in circuit operation frequency necessitates microwave signal sources with good power, stability, and low phase noise characteristics. Frequency multipliers are often utilized to obtain stable microwave frequencies by generating harmonics of stable lower frequency sources.

Diodes or transistors can easily be implemented to generate a second harmonic component (frequency doubler) by utilizing the nonlinear $I-V$ characteristic [1]. However, it is relatively difficult to design frequency triplers due to insufficient power to enhance the third harmonic frequency as compared to the fundamental and second harmonic frequencies.

In previous studies, triplers using diodes or transistors with compatible process of monolithic microwave integrated circuits (MMICs) [2-7] were frequently demonstrated. The commonly used techniques to generate the third harmonic include antiparallel diode pair $[2,3]$ and overdriven transistor $[4,5]$, which requires strong filtering process to remove unwanted harmonics. Some other techniques such as waveform shaping techniques [6], subharmonic mixers [7], and left-handed nonlinear transmission lines [8] were also utilized. When it comes to broad bandwidth and stability, however, the antiparallel diode (Schottky-barrier diode) triplers $[2,3]$, particularly passive diode triplers [3], have been well known for their integrated characteristics of broad bandwidth as compared with transistor $[4,5]$ and varactor triplers [8].

In this paper, two designs of planar wideband antiparallel diode frequency triplers utilizing ultrawideband transitions for phase inversion [9] are presented. The transitions, which act as baluns, are used as input and output matching structures of the proposed triplers with an antiparallel diode pair (APDP). The block diagram of the proposed frequency triplers is shown in Figure 1.

\section{Design of Frequency Triplers}

2.1. Type A Tripler. The layout of the proposed tripler of Type $A$ is shown in Figure 2(a). For input and output matching of the proposed frequency tripler, the planar transitions as shown in Figure 2(b) were implemented following the design guideline by the authors' group [9]. The transitions consist of transitional structures between microstrip line (MSL) and parallel stripline (PSL) and parallel stripline (PSL) and coplanar waveguide $(\mathrm{CPW})$. The input/output transitions are almost symmetrical except for the phase inversion parts between PSL and CPW. To maximize frequency bandwidth, 


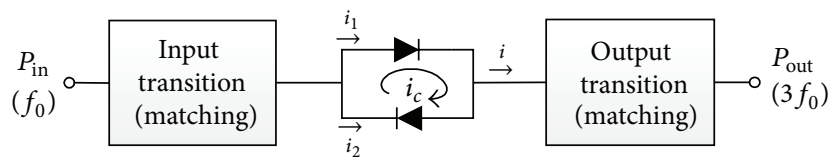

FIGURE 1: Block diagram of the proposed frequency triplers.

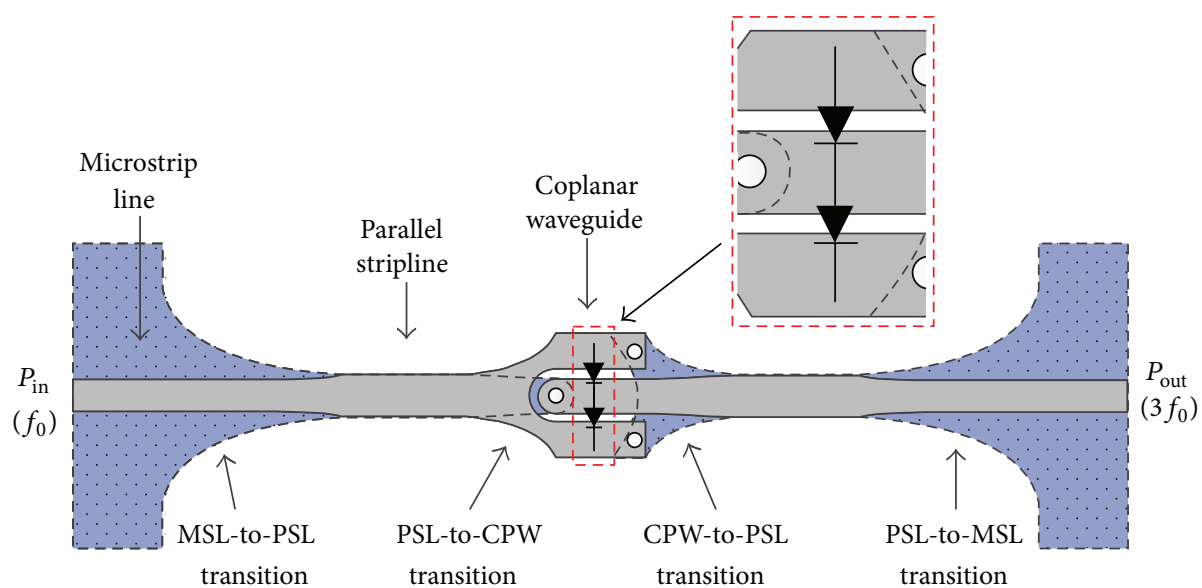

(a)

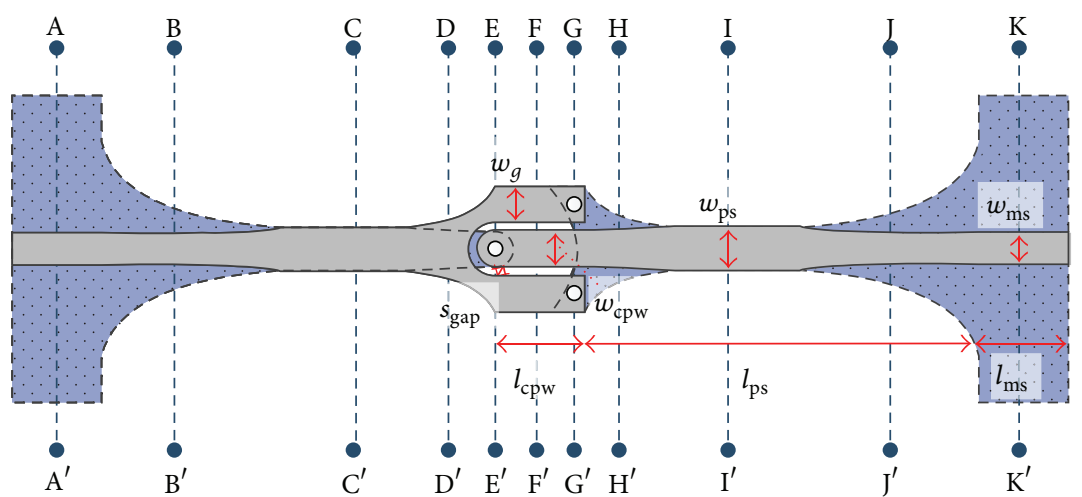

(b)

Figure 2: Proposed frequency tripler (Type A): (a) structure; (b) transition.

TABLE 1: Dimensions for frequency tripler transitions (unit: mil).

\begin{tabular}{cccccccc}
\hline$l_{\mathrm{ms}}$ & $l_{\mathrm{ps}}$ & $l_{\mathrm{cpw}}$ & $w_{\mathrm{ms}}$ & $w_{\mathrm{ps}}$ & $w_{\mathrm{cpw}}$ & $w_{g}$ & $s_{\text {gap }}$ \\
\hline 50 & 220 & 50 & 18 & 24 & 20 & 20 & 5
\end{tabular}

the characteristic impedance at each section of the proposed transition is sustained at $50 \Omega$. The dimensions of the proposed transitions are summarized in Table 1.

To explain the operation of the proposed Type A tripler, it is divided into three parts, that is, (1) MSL-PSL-CPW transition (before diodes), (2) antiparallel diode pair (APDP), and (3) CPW-PSL-MSL transition (after diodes).

First, a transition from MSL to PSL to CPW (A-A' to F$\mathrm{F}^{\prime}$ ) feeds the diodes mounted on the CPW section through its side conductors while the ground is provided at the center conductor. To have proper ground continuity from parallel stripline to CPW, a via hole is utilized to connect the ground conductor of the parallel stripline with the center strip of the CPW (see Figure 2). Figures 3(a) and 3(b) show electric field distributions of the transition at each cross section. In Figure 3(a), it can be observed that there is smooth transformation of electric field lines distributions from MSL (typically vertical) to PSL (typically vertical) and then to CPW (typically horizontal).

Second, the diodes are mounted at the CPW section in such a manner that they act as an antiparallel diode pair (APDP). The diodes are attached to each side conductor of the CPW, and the center conductor strip of the CPW serves as ground (see Figure 2(a)). The APDP works as to generate only odd harmonics while suppressing even harmonics. As described in $[10,11]$, the APDP formed by two identical diodes results in the creation of two different currents, that is, loop current $\left(i_{c}\right)$ and total current $(i)$, as illustrated in Figure 1. 


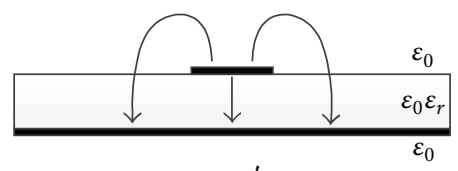

A-A ${ }^{\prime}$

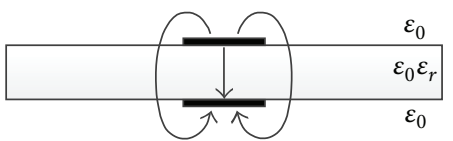

C-C'

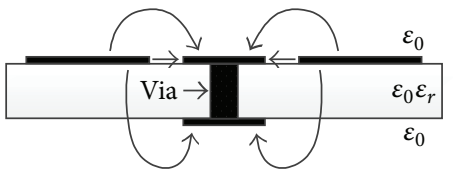

E- $E^{\prime}$

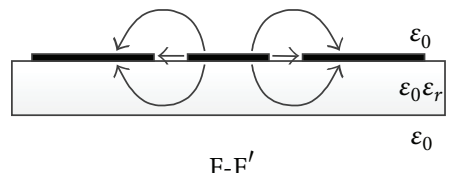

F-F

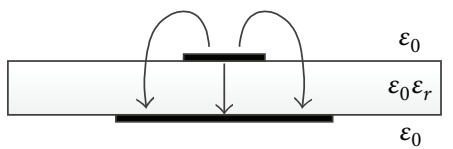

H-H ${ }^{\prime}$

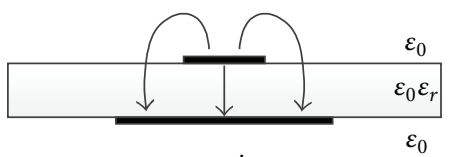

J-J'

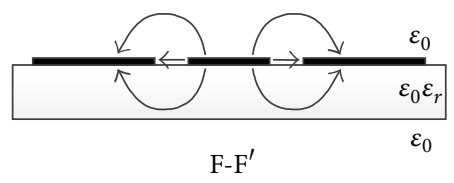

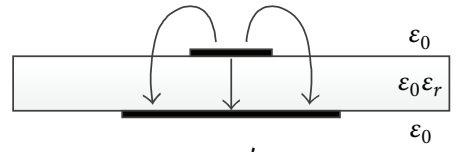

B-B'

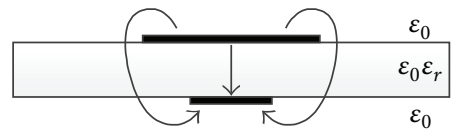

$\mathrm{D}-\mathrm{D}^{\prime}$

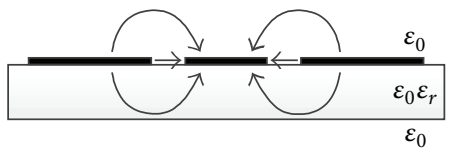

F-F

(a)
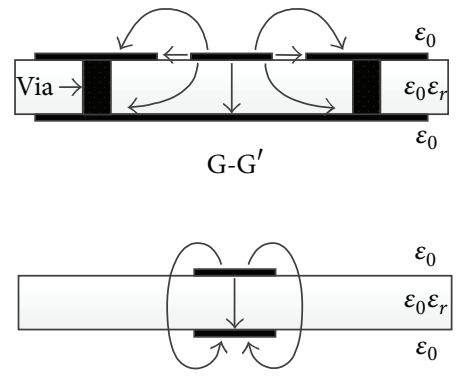

I-I'

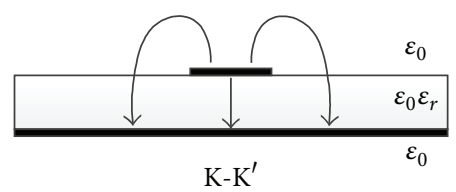

(b)
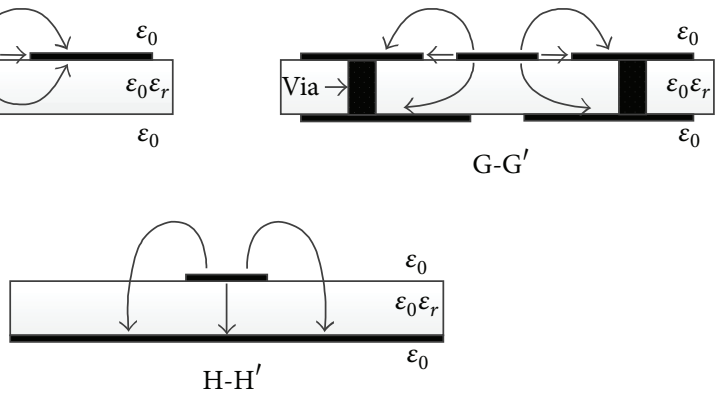

(c)

Figure 3: Electric field line distributions of the transition: (a) MSL-PSL-CPW (Types A and B), (b) CPW-PSL-MSL (Type A), and (c) CPWMSL (Type B).

This $i_{c}$ flows inside the loop of the antiparallel diodes and contains only even harmonics, thus ensuring the suppression of even harmonics, whereas the $i$ has only odd harmonics and flows toward the output.

Third, the output-side transition from CPW to PSL to MSL is utilized. The side conductors of the CPW smoothly transform into the ground plane of the parallel stripline using two via holes, and the center conductor of the CPW is converted into the top conductor of the parallel stripline with a sustained characteristic impedance of $50 \Omega$. The parallel stripline is transformed into microstrip line by changing the width of the top conductor and bottom conductor, while 


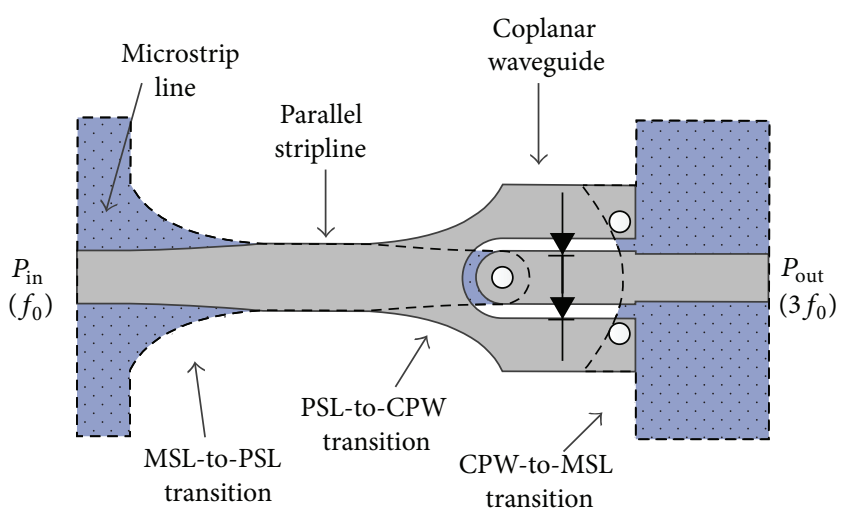

(a)

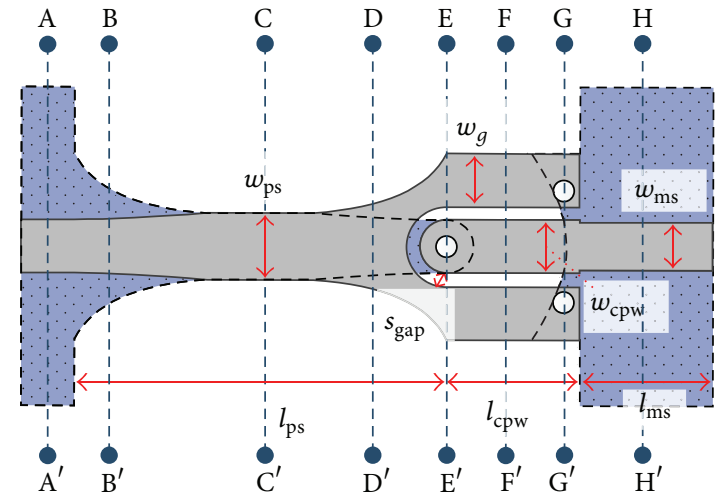

(b)

FIgURE 4: Proposed frequency tripler (Type B): (a) structure; (b) transition.

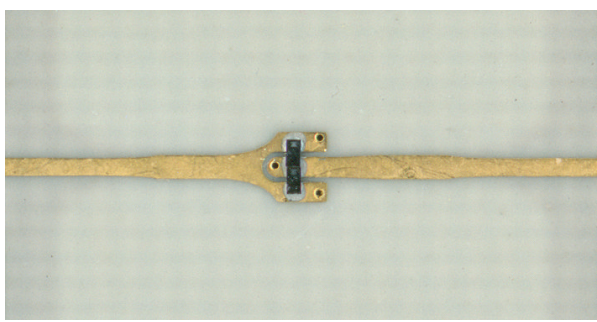

(a)



(b)

Figure 5: Fabricated wideband frequency tripler (Type A): (a) top view and (b) bottom view. The dimension is $540 \mathrm{mil} \times 250 \mathrm{mil}$.

smooth electric field transformation is obtained throughout the transition as shown in Figure 3(b).

\subsection{Type $B$ Tripler. The proposed tripler design of Type B} uses asymmetric baluns. As shown in Figures 4(a) and 4(b), the input-side transition is the same as that in the Type A tripler, but the output-side balun $\left(\mathrm{F}-\mathrm{F}^{\prime}\right.$ to $\left.\mathrm{H}-\mathrm{H}^{\prime}\right)$ is a broadband CPW-to-MSL transition without parallel stripline portion, which results in compact size [9]. The critical aspect of this transition is to provide smooth electric field line transformation from mostly horizontal (CPW) to mostly vertical (MSL) directions. The smooth field transformation between CPW and MSL is obtained by balanced shaping of the ground plane structure $\left(G-G^{\prime}\right)$, and ground continuity is ensured by two via holes positioned at the side conductors of the CPW. Figure 3(c) shows the smooth electric field line transformation of this transition. The characteristic impedance at each section of the transition is again maintained at $50 \Omega$ for the broadband matching.

2.3. Tripler Operation. The operation of the proposed triplers (Types A and B) is summarized as follows. When an RF signal is applied to the microstrip line, it passes through the parallel stripline, and then it is divided into the side conductors of the CPW with the center ground strip, which excites the diodes as an antiparallel diode pair. These paired diodes are turned on and off at every half cycle of the signal causing the generation of currents that contains only odd harmonics of the signal.
The odd harmonic signals are excited at the center conductor of CPW, while transforming the side conductors into the ground. It is worthwhile to mention that the even harmonic components cannot travel through the center conductor of the CPW towards the output port. Likewise, the odd harmonics are unable to travel backwards into the input port because of the APDP and proper grounding. Hence the tripled signal is guided through the transitions towards the output port.

\section{Implementation and Measurements}

3.1. Implementation. For fabrication of the proposed frequency triplers (Types A and B), the Rogers RO4003 substrate with thickness of 8 mil and dielectric constant $\left(\varepsilon_{r}\right)$ of 3.38 is used. The two diodes with a series resistance of $R_{S}=4 \Omega$ and a junction capacitance of $C_{j 0}=0.02 \mathrm{pF}$ (MA-COM MA4E1317) are used to make the APDP.

Figure 5 shows the top and bottom views of the fabricated Type A frequency tripler. The size of the fabricated tripler is $540 \mathrm{mil} \times 250 \mathrm{mil}$. Also, the top and bottom views of the fabricated Type B frequency tripler are shown in Figure 6 . The size of the fabricated Type B tripler is $300 \mathrm{mil} \times 250 \mathrm{mil}$.

3.2. Simulation and Measurements. For nonlinear harmonic balance simulations of the frequency triplers, the AWR Microwave Office circuit simulator was used, and for 3D EM simulations of the planar transitions, the CST Microwave 


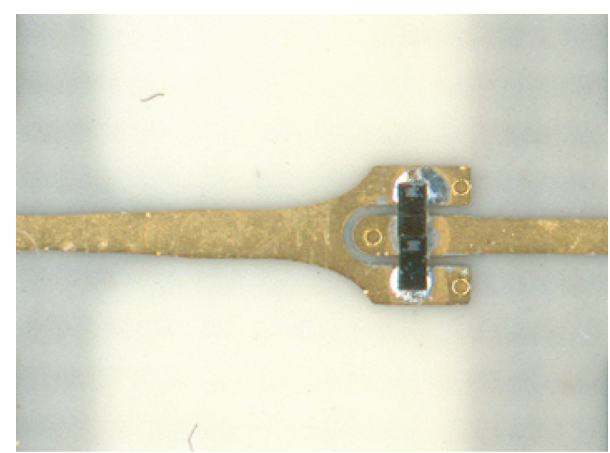

(a)

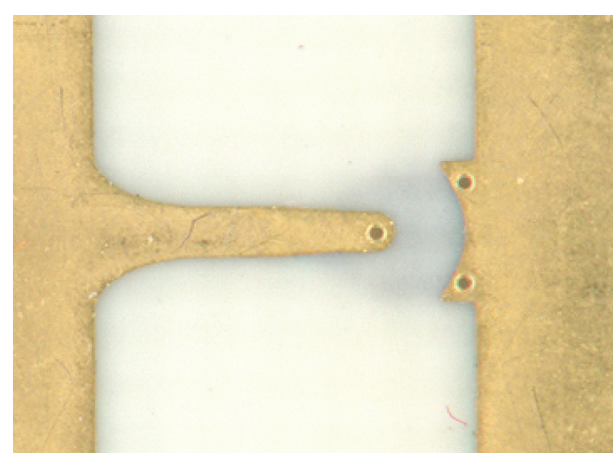

(b)

Figure 6: Fabricated wideband frequency tripler (Type B): (a) top view and (b) bottom view. The dimension is $300 \mathrm{mil} \times 250 \mathrm{mil}$.

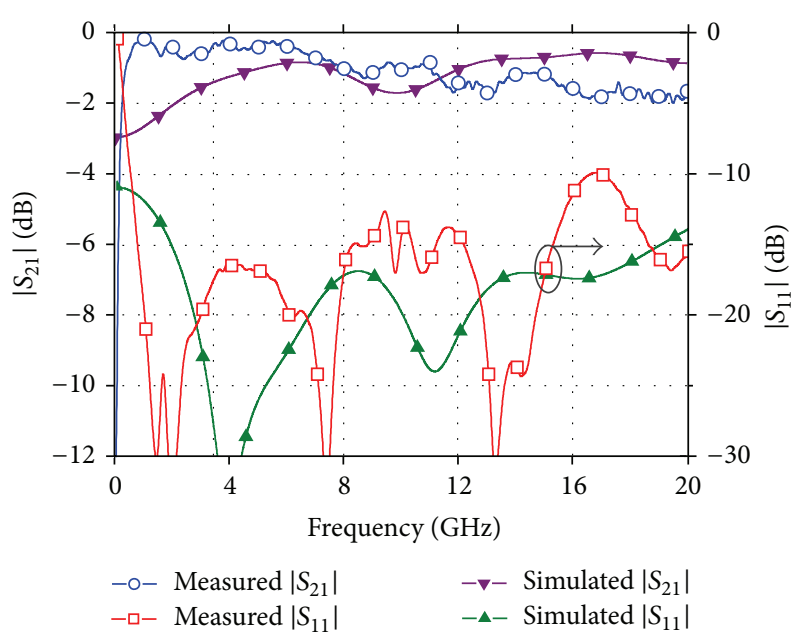

Figure 7: Simulated and measured performance of the Type A transition.

Studio was used. EM simulation results of the transitions were inserted into the nonlinear circuit simulation.

The simulated and measured performances of the ultrawideband transition for Type A are compared in Figure 7. It is observed that transition possesses the insertion loss of average $1.2 \mathrm{~dB}$ as well as the return loss of greater than $10 \mathrm{~dB}$ over the wide frequency range of near DC to $20 \mathrm{GHz}$. Also, Figure 8 compares the simulated and measured performances of an ultrawideband transition [9] for Type B. The transition possesses the insertion loss of average $1.3 \mathrm{~dB}$ with the return loss of greater than $10 \mathrm{~dB}$ over the wide frequency range of near DC to $20 \mathrm{GHz}$.

The performance of the fabricated frequency triplers was measured with the spectrum analyzer and network analyzer. The RF input signal power was $+15 \mathrm{dBm}$. Figure 9 shows the simulated and measured conversion loss of the fabricated Type A tripler. Also, output powers of the 2nd, 3rd, and 4th harmonics with respect to the output frequency are plotted. It can be seen that the tripler possesses the flat conversion loss of about $18 \mathrm{~dB}$ over the wide range of frequencies from 3 to $9 \mathrm{GHz}$. A small disagreement between the simulated and measured conversion loss might have occurred by using

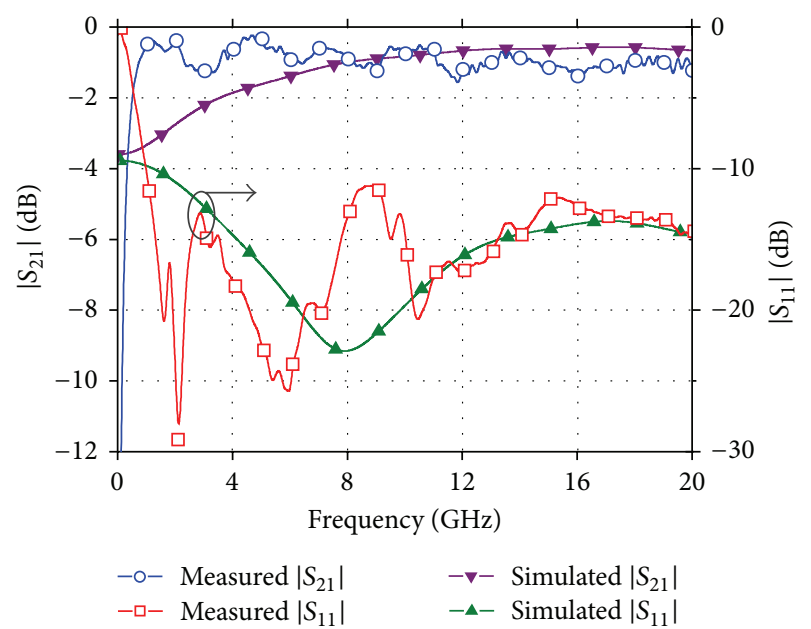

Figure 8: Simulated and measured performance of the Type B transition.

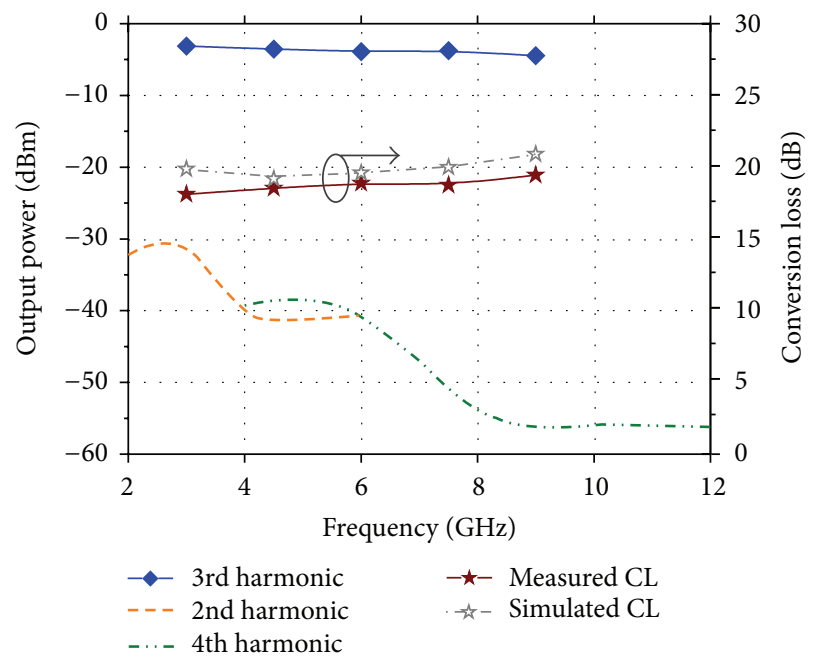

FIGURE 9: Simulated and measured results of conversion loss and measured results of output powers with respect to output frequency (Type A tripler). 
TABLE 2: Performance comparison of the frequency triplers.

\begin{tabular}{|c|c|c|c|c|c|}
\hline & $\begin{array}{c}\text { Tripler } \\
\text { (Type A) }\end{array}$ & $\begin{array}{c}\text { Tripler } \\
\text { (Type B) }\end{array}$ & {$[8]$} & {$[12]$} & {$[13]$} \\
\hline Input freq. (GHz) & $1-3$ & $1-3$ & $2.1-3.4$ & $5.72-6.28$ & $1.8-3$ \\
\hline Input power $(\mathrm{dBm})$ & 15 & 15 & 25 & 5 & 11 \\
\hline Conversion loss $(\mathrm{dB})$ & $18.1-19.4$ & $16.6-18.3$ & $14.2-21.3$ & $16.6-18.5$ & 15 \\
\hline$P_{\mathrm{out}, 3} / P_{\mathrm{out}, 2}(\mathrm{~dB})$ & 30 & 25 & 8 & 44.6 & 55 \\
\hline Size $(\mathrm{mm})$ & $13.71 \times 6.35$ & $7.62 \times 6.35$ & $12 \times 7$ & $6.14 \times 6.28$ & $7.87 \times 6.35$ \\
\hline Nonlinear device & Schottky diode & Schottky diode & Varactor diode & Schottky diode & - \\
\hline
\end{tabular}

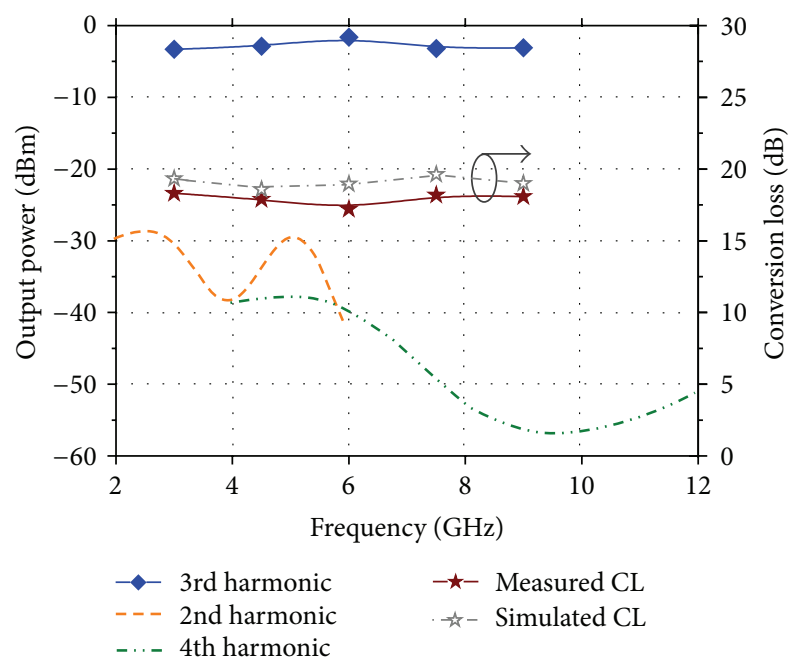

FIgURE 10: Simulated and measured results of conversion loss and measured results of output powers with respect to output frequency (Type B tripler).

SPICE diode model in the nonlinear circuit simulation and by the process of port insertion in EM simulation in order to attach diodes.

It is also noticed that the output powers of even harmonics are much lower than that of the third harmonic. The third harmonic output power is $30 \mathrm{~dB}$ higher than the second harmonic power and $40 \mathrm{~dB}$ higher than the fourth harmonic power. This means that the fabricated tripler can excellently suppress the even harmonics.

The simulated and measured conversion loss of the fabricated Type B tripler are shown in Figure 10, along with the output powers of the $2 \mathrm{nd}$, 3rd, and 4 th harmonics with respect to the output frequency. It is observed that the tripler possesses the flat conversion loss of about $17.2 \mathrm{~dB}$ over the wide range of frequencies from 3 to $9 \mathrm{GHz}$. The output powers of the even harmonic components are again much lower as compared with the tripled signal power.

In order to estimate the influence of a metal structure on the tripler performance, simulations and measurements were also performed with a metal housing (shielding box). If the height of the shielding box is equal to or greater than $80 \mathrm{mil}$ from each side of transitions, the simulated results of planar transitions did not change appreciably from those in Figures 7 and 8 for both Type A and Type B triplers. The performance measurements of the proposed triplers with a shielding box of 120 mil height from each side of the circuit validate the results shown in Figures 9 and 10.

Finally, a performance comparison of the proposed frequency triplers with the previously reported results is summarized in Table 2 . It can be clearly seen that the proposed frequency triplers show competitive performance with wide bandwidth, high even harmonic suppression, and compact size.

\section{Conclusion}

Design procedure and operation principles of the two wideband frequency triplers employing planar transitions are presented in this paper. High even harmonic suppression is achieved due to the use of the ultrawideband transitions and APDP, which helps to keep minimal filtering requirements. Due to wide bandwidth, the proposed triplers may find multiple applications in microwave communication systems where wide bandwidth is required.

\section{Conflict of Interests}

The authors declare that there is no conflict of interests regarding the publication of this paper.

\section{Acknowledgment}

This research was supported by the National R\&D Program through the National Research Foundation of Korea (NRF) funded by the Ministry of Education, Science, and Technology (NRF-2012M1A7A1A02034753).

\section{References}

[1] H. Ogawa and A. Minagawa, "Uniplanar MIC balanced multiplier-a proposed new structure for MIC's," IEEE Transactions on Microwave Theory and Techniques, vol. 35, no. 12, pp. 13631368, 1987.

[2] D. Shim, C. Mao, S. Sankaran, and K. O. Kenneth, "150 Ghz complementary anti-parallel diode frequency tripler in $130 \mathrm{~nm}$ CMOS," IEEE Microwave and Wireless Components Letters, vol. 21, no. 1, pp. 43-45, 2011. 
[3] M. Hrobak, M. Sterns, M. Schramm, W. Stein, and L.-P. Schmidt, "Design and fabrication of broadband hybrid GaAs schottky diode frequency multipliers," IEEE Transactions on Microwave Theory and Techniques, vol. 61, no. 12, pp. 44424460, 2013.

[4] Y. Campos-Roca, C. Schwörer, A. Leuther, and M. SeelmannEggebert, "G-band metamorphic HEMT-based frequency multipliers," IEEE Transactions on Microwave Theory and Techniques, vol. 54, no. 7, pp. 2983-2992, 2006.

[5] J. E. Johnson, G. R. Branner, and J.-P. Mima, "Design and optimization of large conversion gain active microwave frequency triplers," IEEE Microwave and Wireless Components Letters, vol. 15, no. 7, pp. 457-459, 2005.

[6] Y. Zheng and C. E. Saavedra, "A broadband CMOS frequency tripler using a third-harmonic enhanced technique," IEEE Journal of Solid-State Circuits, vol. 42, no. 10, pp. 2197-2203, 2007.

[7] B. R. Jackson, F. Mazzilli, and C. E. Saavedra, "A frequency tripler using a subharmonic mixer and fundamental cancellation," IEEE Transactions on Microwave Theory and Techniques, vol. 57, no. 5, pp. 1083-1090, 2009.

[8] I. B. Kim, K. W. Kim, H. Yoo, J. Park, and H. Kim, "An effective third harmonic generator using a left-handed nonlinear transmisson line," Microwave and Optical Technology Letters, vol. 56, no. 3, pp. 568-570, 2014.

[9] Y.-G. Kim, S.-Y. Song, and K. W. Kim, "A pair of ultra-wideband planar transitions for phase inversion applications," IEEE Microwave and Wireless Components Letters, vol. 20, no. 9, pp. 492-494, 2010.

[10] M. Cohn, J. E. Degenford, and B. A. Newman, "Harmonic mixing with an antiparallel diode pair," IEEE Transactions on Microwave Theory and Techniques, vol. 23, no. 8, pp. 667-673, 1975.

[11] M. V. D. Merwe and J. B. D. Swardt, “The Design and Evaluation of A Harmonic Mixer Using An Antiparallel Diode Pair," Application Note, Microwave Office, http://www.awrcorp.com/download/faq/english/appnotes/harmonic_mixer_diode_pair.aspx.

[12] J.-K. Min, H.-J. Kim, Y.-H. Kim, H.-S. Yu, J.-C. Lee, and U.S. Hong, "Design of a frequency tripler using a novel bandpass filter for Ku-band application," Microwave and Optical Technology Letters, vol. 48, no. 9, pp. 1770-1773, 2006.

[13] RMK-3-93+, Mini-Circuits, http://www.minicircuits.com/. 

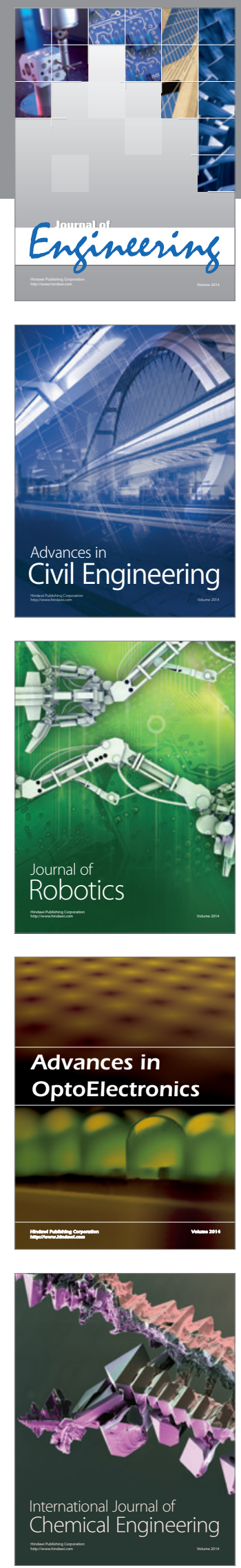

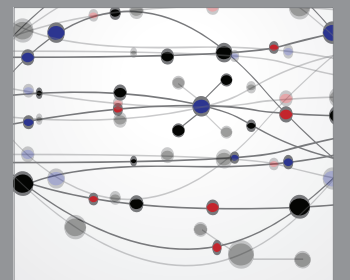

The Scientific World Journal
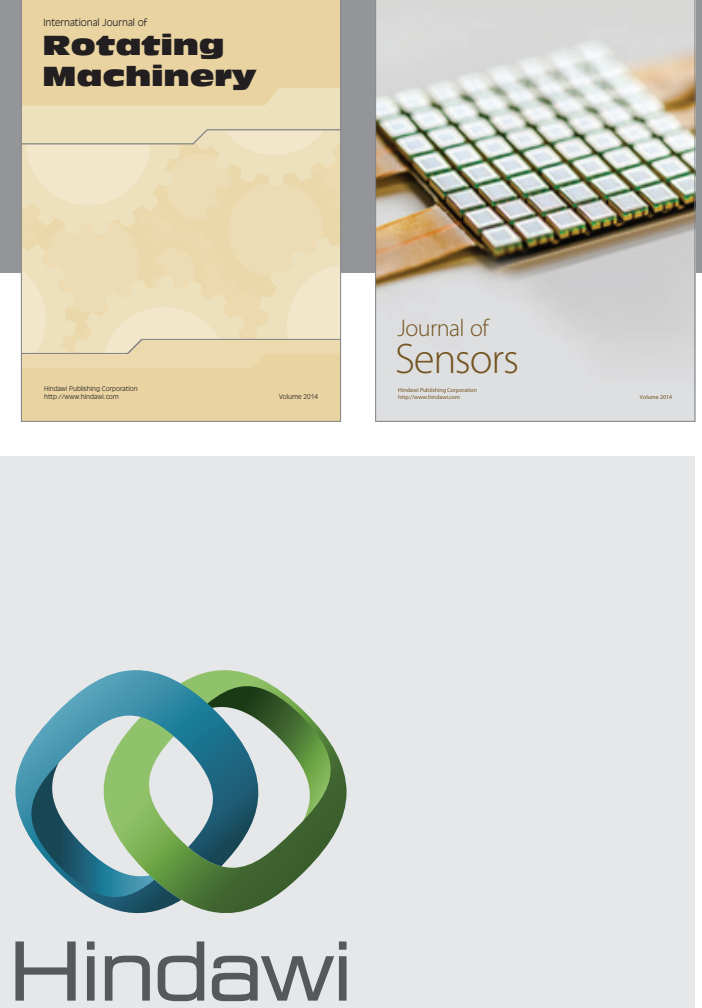

Submit your manuscripts at http://www.hindawi.com
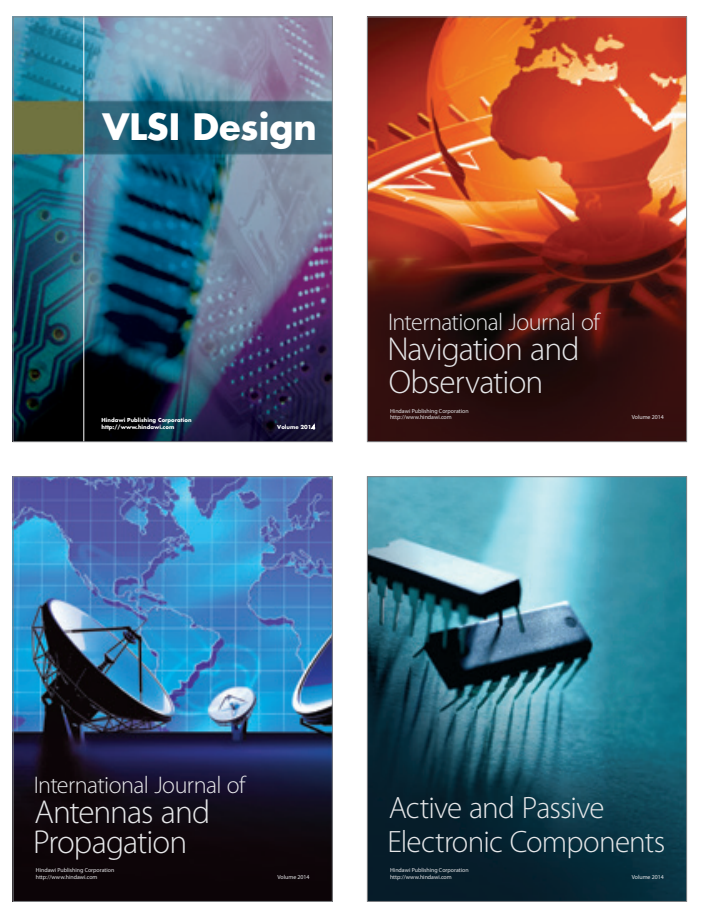
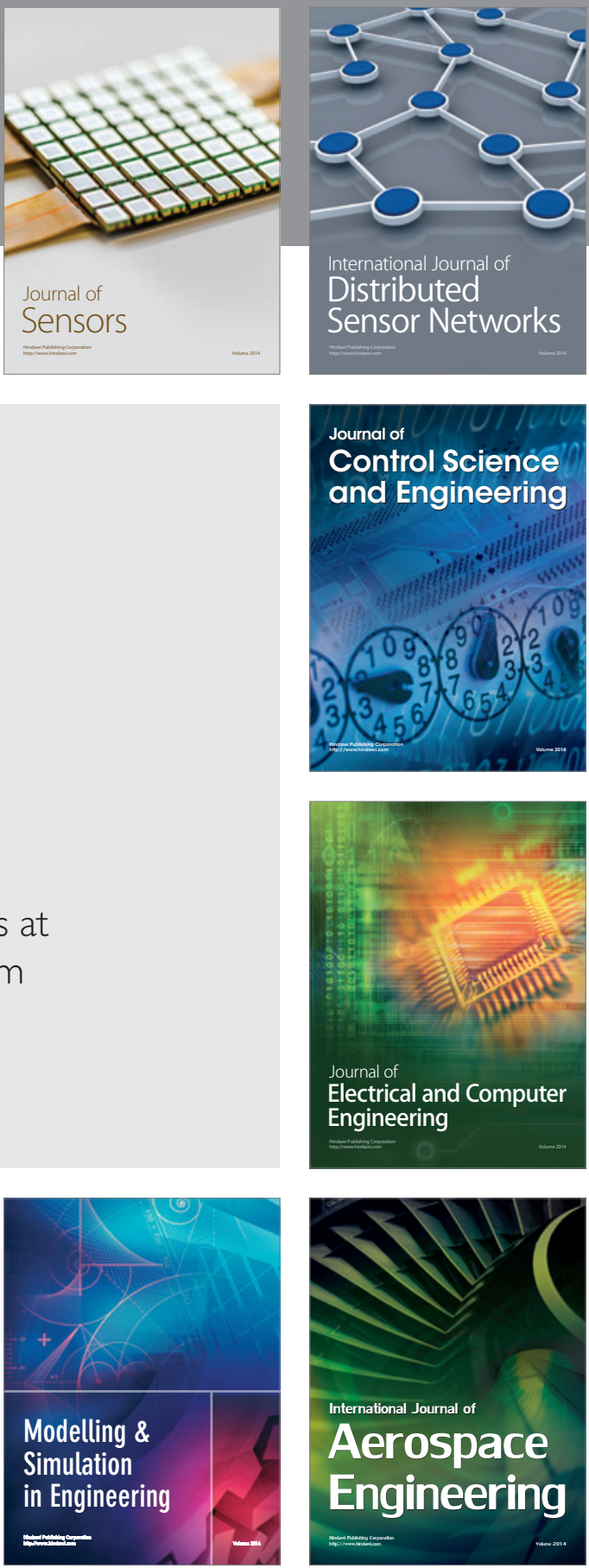

Journal of

Control Science

and Engineering
